Jurnal Health Sains: p-ISSN: 2723-4339 e-ISSN: 2548-1398

Vol. 2, No. 6, Juni 2021

\title{
PENGARUH MIRROR THERAPHY TERHADAP PENINGKATAN KEKUATAN OTOT PADA PENDERITA STROKE
}

\section{Neneng Hasanah, Zahra Maulidia Septimar}

Sekolah Tinggi Ilmu Kesehatan (STIKes) YATSI, Tangerang, Banten, Indonesia

Email: nenenghasanah065@gmail.com, pangeran_jojoy@yahoo.co.id

\begin{tabular}{ll}
\hline ARTIKEL INFO & ABSTRACT \\
\hline Diterima: 5 Juni 2021 & The World Health Organization (WHO) Data shows that \\
Direvisi: 15 Juni 2021 & deaths of 7.9\% of all deaths occurring in Indonesia are caused \\
Disetujui: 25 Juni 2021 & by stroke. According to the data obtained in RSU Kabupaten \\
\hline Keywords: & Tangerang, there are 208 patients suffering from stroke and \\
mirror therapy; muscle & treatment in hospital period from March to May 2020. In \\
strength; stroke; ROM & patients with stroke will usually experience weakness in \\
& muscles based on some research gained that one of the \\
& complementary therapies that can be performed in a non- \\
& hemorrhagic stroke patients is mirror therapy. Mirror \\
& Therapy is the shape motoric imagination that is expectable \\
& visual, mental performance of a movement without doing the \\
& movement. The study aims to collect and analyze articles \\
& related to the intervention of increasing the muscle strength \\
of the stroke sufferers with Mirror Therapy. The design used is & the Literature Review, articles gathered by using the search \\
engine Google Scholar, PUBMED, Medline and Resarchgate. & The article criteria used were published in 2014-2020. Based \\
on the article collected the results that Mirror Therapy proved & to improve muscle strength in Stroke patients. Mirror Therapy \\
can also be combined with other therapies such as ROMS, \\
acupresure, and motivation supportagainst Stroke patients. \\
The role of nurses in giving therapy and support to patients is \\
also very influential. Mirror Therapy will be more effective in \\
enhancing muscle strength in stroke patients when done \\
routinely and disciplined.
\end{tabular}

\begin{abstract}
ABSTRAK
Data World Health Organization (WHO) menunjukkan bahwa kematian sebesar 7,9\% dari seluruh kematian yang terjadi di Indonesia disebabkan oleh stroke. Menurut data yang di peroleh di RSU Kabupaten Tangerang, terdapat 208 pasien yang menderita stroke dan menjalani perawatan di rumah sakit periode maret hingga mei 2020. Pada penderita stroke biasanya akan mengalami kelemahan pada otot berdasarkan beberapa penelitian didapatkan bahwa salah satu terapi komplementer yang dapat dilakukan pada pasien strokenon hemoragik adalah mirror therapy. Mirror = therapy adalah bentuk= imajinasi motoric yang ekspektasikan secara=visual, mental=performance dari suatu gerakan tanpa melakukan gerakan tersebut. Penelitian ini bertujuan untuk
\end{abstract}

$\begin{array}{ll}\text { How to cite: } & \text { Hasanah, Neneng. Zahra Maulidia Septimar. (2021). Pengaruh Mirror Theraphy terhadap Peningkatan } \\ & \text { Kekuatan Otot pada Penderita Stroke. Jurnal Health Sains 2(6). https://doi.org/10.46799/jhs.v2i6.194 } \\ & 2723-6927 \\ \text { E-ISSN: } & \text { Ridwan Institute } \\ \text { Published by: } & \end{array}$


Kata Kunci:

mirror therapy; kekuatan otot; stroke; ROM mengumpulkan dan menganalisa artikel yang berhubungan dengan intervensi Meningkatkan kekuatan otot penderita stroke dengan mirror therapy. Desain penelitian yang digunakan adalah literature review, artikel dikumpulkan dengan menggunkan mesin pencarian google scholar, PUBMED, Medline dan Resarchgate. Kriteria artikel yang digunakan adalah diterbitkan pada tahun 2014-2020. Berdasarkan artikel yang dikumpulkan didapatkan hasil bahwa Mirror Therapy terbukti dalam meningkatkan kekuatan otot pada pasien Stroke. Mirror Therapy juga dapat dikombinasikan dengan terapi lain seperti ROM, Akupresure, dan dukungan Motivasi terhadap pasien Stroke. Peran perawat dalam memberi terapi dan dukungan kepada pasien juga sangat berpengaruh. Mirror Therapy akan lebih efektif dalam meningkatkan kekuatan otot pada pasien stroke apabila dilakukan secara rutin dan disiplin.

\section{Pendahuluan}

Penyakit Tidak Menular (PTM) adalah penyebab kematian hamper $70 \%$ di dunia (Pratama et al., 2020). PTM adalah penyakit kronis yang tidak ditularkan dari orang ke orang. Jenis PTM diantaranya adalah penyakit jantung, stroke, kanker, diabetes, dan Penyakit Paru Obstruktif Kronis (PPOK).Di Indonesia, stroke merupakan penyakit nomor tiga mematikan setelah jantung dan kanker (RI, 2016).

Stroke merupakan suatu keadaan defisit neurologis yang terjadi ketika sebagian sel-sel otak mengalami kematian akibat gangguan aliran darah karena sumbatan atau pecahnya pembuluh darah di otak (Al Kasab et al., 2017).

Badan organisasi kesehatan dunia, World Health Organization (WHO) mendefinisikanstroke sebagai gangguan suplai darah pada otak yang biasanya karena pecahnya pembuluh darah atau sumbatan oleh gumpalan darah. Hal ini menyebabkan gangguan pasokan oksigen dan nutrisi di otak

sehingga terjadi kerusakan jaringan otak.

Stroke diklasifikasikan menjadi dua yaitu iskemik dan hemoragik (Organization, 2013).

Pada penderita stroke biasanya akan mengalami kelemahan pada otot berdasarkan beberapa penelitian didapatkan bahwa salah satu terapi komplementer yang dapat dilakukan pada pasien stroke non hemoragik adalah mirror therapy (Fariyanti et al., 2020).

Data World Health Organization (WHO)menunjukkan bahwa kematian sebesar $7,9 \%$ dari seluruh kematian yang terjadi di Indonesia disebabkan oleh stroke

Kementrian kesehatan Republik Indonesia menyatakan Hasil Riset Kesehatan Dasar (Riskesdas) pada tahun 2013-2018 wawancara yang dilakukan berdasarkan diagnosis dokter kejadian stroke di Indonesia adalah 10,9\% (Permil) dan Banten merupakan urutan ke 13 dari 34 provinsi yang ada di Indonesia (Riskesdas, 2013).

Menurut data yang di dapat selama 3 bulan terakhir di RSU Kabupaten Tangerang, terdapat 208 pasien yang menderita stroke dan menjalani perawatan di rumah sakit (Muliawati, 2016).

Berdasarkan penelitian yang dilakukan oleh (Setyawan, 2019) Peneitian ini melibatkan dua kelompok yaitu kelompok perlakuan yang akan di berikan terapi cermin dan kelompok kontrol hanya diberikan terapi Latihan Range Of Movement. Dari hasil penelitian menunjukan hasil bahwa terdapat peningkatan kekuatan otot pada pasien stroke yang sudah diberikan mirror therapy. 


\section{Metode Penelitian}

Desain penelitian ini menggunakan metode studi kepustakaan atau literature review. Format pencarian digunakan untuk mendapatkan hasil artikel full-text yang sesuai dengan kata kunci pencarian mirror therapy, kekuatan otot, dan Stroke dengan menggunakan format PICOT (population, intervension, comparasion, outcome and time). PICO merupakan metode pencarian klinis sebagai rancangan literature review (Hanifah, 2015).

$\mathrm{P}$ : Stroke

I : Mirror Theraphy

C: Tidak ada

O: efektivitas mirror theraphy terhadap peningkatan kekuatan otot

T: 15-30 Menit dalam 1 hari

Data yang digunakan dalam penelitian ini didapat dari hasil penelitian yang sudah diakukan dan diterbitkan dalam jurnal online. Dalam penelitian ini peneliti menggunakan pencarian jurnal yang di publikasikan melalui search engine researchgate, Google Scholar, PUBMED dan medline dengan kata kunci: mirror therapy, kekuatan otot, dan Stroke.

Strategi pencarian literature berdasarkan diagram flow PRISMA. Proses pengumpulan data dilakukan dengan penyaringan berdasarkan kriteria yang sudah di tentukan dari setiap jurnal

\section{Hasil dan Pembahasan}

Bedasarkan 2 artikel yang sudah di analisis mempunyai metode penelitian yang berbeda diantaranya adalah quasyeksperiment, experimental, dan one group test design. Tempat penelitian dalam artikel tersebut ada yang dilakukan di Indonesia dan Luar negri. Dalam ke 19 artikel yang di temukan terdapat intervensi dan terapi yang bervariasi untuk meningkatkan kekuatan otot. Tidak ahanya dengan mirror therapy tetapi

dengan terapi latihan ROM, akupresure, serta rehabilitasi fisioterapi, namun yang akan dibahas dalam literature review ini adalah bagaimana pengaruh atau efektivitas mirror therapy terhadap kekuatan otot pada pasien stroke. Gangguan motoris pada pasien stroke biasanya akan mengalami kelemahan otot hingga kelumpuhan pada sisitubuhnya sehingga pasien stroke akan kehilangan gerak dan perasaan meraba pada bagian lengan atau kaki. Pada pasien stroke yang mengalami stroke pada otak kirinya, ia bias mengalami stroke pada bagian lengan kanan atau kaki kanannya (Romidoni, 2020). Hal ini dapat menyulitkan pasien untuk beraktivitas seharihari. Efek defisit motoris ini juga meliputirasa sakit, kelelahan, perubahan tonus otot serta gangguan berjalan (Hankey et al., 2014).Dari 19 daintaranya menunjukan hasil bahwa mirror therapy sangat efektif terhadap meningkatkan kekuatan otot pada pasien stroke. Penelitian yang dilakukanpun beragam ada yang menggunakan mirror theraphy lalu dikombinasikan dengan terapi lain ada juga yang membandingkan mirror therapy dengan terapi lain. Peningkatan kekuatan otot terlihat pada hasil seduah dilakukan Mirror Terapi dengan durasi waktu 15-30 menit. Responden atau partisipan yaitu kisaran usia 25 hingga 60 tahun (Lobmann et al., 2005). Terapi cermin terbukti lebih baik dibanding terapi rehabilitasi standar. Terapi ini juga bermanfaat pada stroke fase akut, subakut, dan kronis, serta dapat diintegrasikan pada terapi rehabilitasi stroke untuk meningkatkan fungsi motorik ekstremitas atas (Machyono et al., 2018).

Penulis menemukan penelitian yang dilakukan oleh (Shabaani Mehr et al., 2019) yang menyatakan bahwa tidak ada perbedaan yang signifikan antara kelompok intervensidan kelompok kontrol pada peningkatan kekuatan otot. Akan tetapi kelompok intervensi yang dilakukan mirror therapy menunjukan peningkatan kemampuan berjalan yang lebih signifikan dibandikan 
dengan kelompok kontrol. Pada individu yang normal Membayangkan anggota tubuhnya bergerak dapat mengaktifkan korteks premotor, kortecs motoric primer, dan juga lobuus parietal. Studi penelitian membuktikan bahwa ada beberapa nous pada sistem motoric yang menghasilkan gerakan, mengamati gerakan, memahami dan mengenali alat sebagai objek gerakan. Dengan membayangkan suatu gerakan akan menyebabkan kurang lebih $30 \%$ neuron MI aktif dan mengeksekusi gerakan yang sedang dibayangkan.

Peningkatan kekuatan otot pada penderita stroke di pengaruhi oleh terapi latihan yang rutin dilakukan dan juga dukungan dari orang terdekat agar pasien dapat termotivasi untuk melakukan terapi yang rutin dan disiplin (Meytasari, 2017). Gerakan motoric pada tangan yang sehat akan menimbulkan umpan balik pada sensoorifisual ke otak. Intervensi yang sering dilakukan dilakukan dan diarahpkan pasien agar dapat cepat sehat dan dapat beraktivitas seperti biasa.pada naggota gerak yang mengalami hemiparesis.

Kelemahan dalam metode ini adalah perlunya terapi lain yang dilakukan secara rutin serta peningkatan kekuatan otot yang memerlukan waktu yang lama agar pasien bisa pulih serta metode yang digunakanefektiv.

\section{Kesimpulan}

Berdasarkan.hasil dari pencarian artikel yang didapatkan oleh peneliti maka dapat disimpulkan bahwa Mirror Therapy terbukti efektif dalam meningkatkan kekuatan otot pada pasien stroke. 19 jurnal dan artikel yang diterbitkan sesuai dengan kriteria inklusi mulai dari tahun 2014 hingga tahun 2019 menunjukan hasil yang sama yaitu dapat meningkatkan kekuatan otot secara bertahap. Mirror therapy juga dapat dikombinasikan dengan terapi lain dengan cara rutin dilakukan dan dengan prosedur yang benar.

\section{BIBLIOGRAFI}

Al Kasab, S., Adams, R. J., Debenham, E., Jones, D. J., \& Holmstedt, C. A. (2017). Medical University Of South Carolina Telestroke: A Telemedicine Facilitated Network For Stroke Treatment In South Carolina-A Progress Report. Telemedicine And E-Health, 23(8), 674677. Google Scholar

Fariyanti, C., Priyanto, P., \& Sukarno, S. (2020). Studi Literatur Tentang Pengaruh Intervensi Terapi Cermin Pada Pasien Stroke Di Rumah Sakit. Universitas Ngudi Waluyo. Google Scholar

Hanifah, N. Z. (2015). Uji Toksisitas Akut Ekstrak Metanol Daun AnnonaMuricata L Terhadap Larva Artemia Salina Leach Dengan Metode Brine Shrimp Lethality Test (Bslt). Jakarta: Fakultas Kedokteran Dan Ilmu Kesehatan Uin Syarif Hidayatullah, 2015. Google Scholar

Hankey, G. J., Norrving, B., Hacke, W., \& Steiner, T. (2014). Management Of Acute Stroke In Patients Taking Novel Oral Anticoagulants. International Journal Of Stroke, 9(5), 627-632. Google Scholar

Lobmann, R., Schultz, G., \& Lehnert, H. (2005). Proteases And The Diabetic Foot Syndrome: Mechanisms And Therapeutic Implications. Diabetes Care, 28(2), 461-471. Google Scholar

Machyono, M., Tammasse, J., Kaelan, C., Muis, A., \& Ganda, I. J. (2018). Efektivitas Terapi Cermin Terhadap Perbaikan Motorik Lengan Pasien Stroke Iskemik Akut. Majalah Kedokteran Neurosains Perhimpunan Dokter Spesialis Saraf Indonesia, 35(2). Google Scholar

Meytasari, H. W. (2017). HubunganDukungan Pasangan Hidup Dengan Kepatuhan Mengontrol Tekanan Darah 
Pada Pasien Hipertensi Di Puskesmas Kendalsari Kota Malang. Universitas Brawijaya. Google Scholar

Muliawati, S. (2016). Studi Deskriptif Pelaksanaan Teknik Menyusui Bayi Tunggal Di Rb Mta Semanggi Surakarta Tahun 2011. Jurnal Infokes Universitas Duta Bangsa Surakarta, 2(1). Google Scholar

Organization, W. H. (2013). Transforming And Scaling Up Health Professionals, Education And Training: World Health Organization Guidelines 2013. World Health Organization. Google Scholar

Pratama, S., Susanto, H. S., \& Warella, Y. (2020). Program Pos Pembinaan Terpadu Penyakit Tidak Menular Di Daerah Kepulauan. Higeia (Journal Of Public Health Research And Development), 4(2), 312-322. Google Scholar

Ri, K. (2016). Kementerian Kesehatan Republik Indonesia. 2018. Pedoman Umum Gizi Seimbang. Jakarta (Id): Direktorat Jenderal Bina Kesehatan
Masyarakat. Google Scholar

Riskesdas. (2013). Riskesdas 2013. In Jakarta Kementeri Kesehat Ri (Vol. 6). Google Scholar

Romidoni, M. (2020). Asuhan Keperawatan Keluarga Tn. S Dan Tn. J Pasca Stroke Dengan Masalah Keperawatan Hambatan Mobilitas Fisik Di Wilayah Kerja Puskesmas Rogotrunan Kabupaten Lumajangtahun 2018. Google Scholar

Setyawan, C. E. (2019). Studi Hadits: Analisis Terhadap Pemikiran Schacht Dan A'zami. Jurnal Kajian Islam Interdisipliner, 1(2). Google Scholar

Shabaani Mehr, M., Khaleghdoost Mohammadi, T., Jafroudi, S., Kazemnezhad Leyli, E., \& Majd Teimoori, Z. (2019). The Effect Of Mirror Therapy On The Walking Ability Of Patients After Stroke. Journal of Holistic Nursing And Midwifery, 29(4), 200-209. Google Scholar

\section{Copyright holder:}

Neneng Hasanah, Zahra Maulidia Septimar (2021)

\section{First publication right:}

Jurnal Health Sains

This article is licensed under: 